удК 159.922.4

Е. Л. Трофимова

Байкальский государственный университет, г. Иркутск, Российская Федерация

T. А. Терехова

Иркутский государственный университет,

2. Иркутск, Российская Федерация

\title{
МЕЖЭТНИЧЕСКОЕ ВЗАИМОДЕЙСТВИЕ СТУДЕНТОВ ИЗ СТРАН АТР КАК УСЛОВИЕ ПСИХОЛОГИЧЕСКОЙ БЕЗОПАСНОСТИ
}

\begin{abstract}
АНнотАцИЯ. В статье проанализированы особенности межэтнического взаимодействия студентов китайской и монгольской национальностей, обучающихся в вузах г. Иркутска, показано воздействие на характер межэтнического взаимодействия традиционных культурных установок. Приведены результаты выявленных различий содержания гражданской идентичности, этнической идентичности, толерантности, культурно-ценностных ориентаций и социальной дистанции в общении. Специфичность стратегии адаптации китайцев и монголов к культуре других этносов заключается в том, что при наличии эмоционального дискомфорта, они сохраняют высокую степень ощущения себя частью своего государства и народа. У китайских и монгольских студентов проявляется озабоченность своей национальной безопасностью и осторожным отношением к проявлениям толерантности в отношении других народов. Обособленность компонентов гражданской идентичности китайских студентов является тем стержнем, который позволяет сохранять традиционные корни китайской культуры, проявляющиеся в современной культуре и успешно адаптироваться в инокультурной среде. Исследование выявленных особенностей будет способствовать обеспечению более надежных и доверительных отношений в среде студентов-мигрантов из стран АТP, как на межгрупповом, так и на межличностном уровне.

кЛЮЧЕВЫЕ сЛОВА. Межэтническое взаимодействие; образовательная миграция; китайцы; монголы; кризисная ситуация; этническая толерантность; межкультурная компетентность; гражданская идентичность; этническая идентичность; психологическая безопасность.
\end{abstract}

ИНФОРМАЦИЯ О СТАТЬЕ. Дата поступления 24 октября 2017 г.; дата принятия к печати 19 декабря 2017 г.; дата онлайн-размещения 29 декабря 2017 г.

Ye. L. Trofimova Baikal State University, Irkutsk, Russian Federation

T. A. Terekhova

Irkutsk State University, Irkutsk, Russian Federation

\section{INTERETHNIC INTERACTION OF STUDENTS FROM THE APR COUNTRIES AS A CONDITION OF PSYCHOLOGICAL SECURITY}

\begin{abstract}
The article analyzes the features of interethnic interaction between students of Chinese and Mongolian nationalities studying at Irkutsk Universities and shows the impact of the traditional cultural settings on the character of interethnic interaction. The article reveals the results of differences in the civil identity contents, ethnic identity, tolerance, cultural-value orientations and social distance in communication. The specificity of an adapting strategy of the Chinese and of the Mongol in terms of culture of other ethnic groups stands in retaining a high level of feeling themselves as a part of their state and people in the presence of an emotional
\end{abstract}

(C) Е. Л. Трофимова, Т. А. Терехова, 2017

\section{Baikal Research Journal}

электронный научный журнал Байкальского государственного университета 
discomfort. The Chinese and Mongolian students get concerned about their national security and careful attitude to the manifestation of tolerance towards other nations. The isolation of the civic identity components of the Chinese students is the core that allows to preserve the traditional roots of the Chinese culture, that appear in the modern culture, and successfully adaptation in the foreign culture environment. The study of the revealed features will help to provide more reliable and trusting relations among migrant students from the APR countries, both at the intergroup and interpersonal levels.

KEYWORDS. Interethnic interaction; educational migration; Chinese; Mongols; crisis situation; ethnic tolerance; intercultural competence; civic identity; ethnic identity; psychological security.

ARTICLE INFO. Received October 24, 2017; accepted December 19, 2017; available online December 29, 2017.

Поступление в колледж, вуз значимое событие в жизни каждого человека, новая веха его жизненного пути. Тем не менее, даже самое радостное событие может рассматриваться как трудная жизненная ситуация, «когда нарушается упорядоченность течения жизни человека, и он не может решить ту или иную проблему с помощью привычных схем поведения» [1, с. 150] и студенту необходимо адаптироваться к новому распорядку дня, новым требованиям, новому коллективу. Для инокультурных студентов переезд в другую страну может стать не только трудной, но и кризисной ситуацией. Кризисная ситуация определяется «как взаимодействие субъекта со средой в процессе его функционирования, когда субъект сталкивается с невозможностью дальнейшего успешного существования на основе имеющихся в его распоряжении ресурсов. Для преодоления (переживания) кризисной ситуации от субъекта требуется результативная психическая работа по перестройке своего функционирования (часто на пределе возможностей)» [1]. В качестве стрессоров могут выступать иной язык, культура, традиции принимающей страны, различия ценностных ориентаций, специфика решения бытовых вопросов, например, особенности приготовления пищи, отношение со стороны студентов, представляющих коренное население и студентов других национальностей.

Последний фактор в современных политических условиях, когда многие страны захлестнули миграционные проблемы, приобретает все большую остроту и потенциально, как для инокультурных студентов, так и для принимающей стороны может рассматриваться как угрожающий их психологической безопасности.

Психологическая безопасность личности проявляется «в ее способности сохранять устойчивость в среде с определенными параметрами, в том числе и с психотравмирующими воздействиями, сопротивляемости деструктивным внутренним и внешним воздействиям и отражается в переживании своей защищенности/ незащищенности в конкретной жизненной ситуации» [2, с. 110].

Не случайно феномен миграции (в узком смысле, с позиции иммиграции/ эммиграции) стал изучаться в контексте кризисных и экстремальных ситуаций [1]. Значительную часть миграционного потока, доля которой имеет тенденцию к росту, составляют студенты-мигранты, соответственно появляются исследования проблем образовательной (учебной) миграции [3; 4]. Авторы обращают внимание на то, что, с одной стороны, «в условиях усиления миграционных потоков в мировом масштабе образовательных мигрантов можно считать самой желательной категорией, поскольку, как правило, ее составляют молодые и инициативные люди, которые отличаются открытостью и готовностью воспринимать новые знания и технологии...», отмечают, что «учебная иммиграция имеет огромное социальное значение для многих стран, и для развития России в частности, и несет, как ми-

\section{Baikal Research Journal}

электронный научный журнал Байкальского государственного университета 
нимум, четыре ключевых эффекта: социальный, политический, демографический и экономический» [3]. В то же время, именно студенты становятся наиболее активными участниками межэтнических конфликтов, распространяют ксенофобические и экстремистские установки. Сложившиеся в советские времена партнерские и даже дружеские связи с Монголией и Китаем в постсоветском пространстве сохраняются, но меняется динамика, характер, сфера контактов, что приводит к изменению устоявшихся стереотипов. Особое внимание привлекает китайская диаспора, интенсивный приток в восточные регионы представителей китайского этноса вызывает опасения перед китайской экспансией. Более выраженным стало поле отрицательной коннотации стереотипов по отношению к мигрантам «дальнего» зарубежья, в том числе из стран АТР. Но, с другой стороны, меняется менталитет современного поколения, как мигрантов, так и принимающей стороны, наблюдаются признаки глобализации и синкретизма культур, этому способствует активность межличностных контактов, открытость границ, использование продукции транснациональных корпораций, интернет - экономика и пр. В зарубежной литературе появилось описание нового феномена «текучего общества», которое рассматривается как альтернатива традиционному обществу. Х. Койпп выделяет ряд признаков «текучего общества»: плюрализация, деконструкция половых ролей, индивидуализация, изменение ценностей, утрата традиционности, глобализация, дигитализация и как следствие возникновение синдромов «возрастающей мобильности, социальной изоляции, изменения ценностных ориентаций». Основные черты «текучего общества», по мнению автора, следующие:

а) утрата границ (безграничное виртуальное пространство, плюрализм ценностей, генная инженерия, пластическая хирургия);

б) слияние (работа - свободное время: мобильный офис, классическая культура - попкультура, конвергенция медийных технологий);

в) проницаемость (электронная коммерция, дистанционное воз-действие - peальное время, публичность - вебкамеры, изменяющиеся фазы жизни - «старые-молодые»);

г) меняющиеся конфигурации (гибкая организация труда, смешанные семьи - сообщества на время, модульные концепции в технике, воздействие изменяющейся рекламы, моды, музыки) [1, С. 238].

Какова специфика межэтнического взаимодействия в восточных регионах России, актуальной ли остается задача сохранения прежней культурной идентичности для местного населения и мигрантов, приобретает ли наше общество характеристики «текучести» и можно ли это рассматривать как угрозу? Мы проанализируем особенности межэтнического взаимодействия на примере студентов из стран АТР, обучающихся в вузах г. Иркутска.

В исследовании приняли участие 80 студентов подготовительного факультета, среди них студенты китайской национальности составили 40 респондентов; студенты монгольской национальности - 40 респондентов в возрасте от 18 до 22 лет. Предполагаем, что сложности адаптационного периода могут быть связаны с тем, что в условиях аккультурации для инокультурных студентов возможна конкуренция отдельных компонентов их этнической и гражданской идентичности с компонентами межкультурной компетентности, толерантностью, ценностными ориентациями.

В процессе работы была составлена анкета, включающая следующие стандартизированные методики: авторский опросник гражданской идентичности; методика «Типы этнической идентичности» (Г.У. Солдатова, С.В. Рыжова); экспресс-опросник «Индекс толерантности» (Г.У.Солдатова, О.А.Кравцова, О.Е. Хухлаев, Л.А.Шайгерова); методика определения уровня перцептивно-невербальной ком-

\section{Baikal Research Journal}


петентности (Г.Я. Розен); тест культурно-ценностных ориентаций (Дж. Таусенд, вариант Л. Г. Почебут); шкала социальной дистанции Э.Богардуса [5; 6; 7].

Проведенное эмпирическое исследование, направленное на выявление особенностей межэтнического взаимодействия студентов из стран АTP позволило сделать вывод о наличии различного рода особенностей в проявлении гражданской идентичности, этнической идентичности, толерантности, а также в трактовке и понимании культурно-ценностных ориентаций.

\section{Гражданская идентичность}

Для китайских студентов характерен высокий уровень гражданской идентичности, однако компоненты гражданской идентичности имеют только внутренние связи, причем когнитивный компонент отрицательно коррелирует с эмоциональным $(\mathrm{r}=-0,420, \mathrm{p}=0,001)$ и поведенческим $(\mathrm{r}=-0,366, \mathrm{p}=0,007)$, таким образом, чем выше степень осознания своей принадлежности к государству, своих гражданских прав и обязанностей, тем менее выражены позитивная эмоциональная окраска и поведенческие реакции. Возможно, это связано, с одной стороны, с восприятием своей страны как супер-державы («срединного» государства) одной из древнейших цивилизаций, с другой стороны, со сдержанностью китайцев в чужой для себя культурной среде, умение сохранять автономность. Анализ истории межкультурных контактов Китая в контексте конфуцианской дихотомии «культурная ассимиляция - экспансия», раскрывает сущность взаимодействия Китая с другими культурами. Кочевым соседним племенам, иностранным государствам, нападающим на Китай, удавалось физически завоевать Китай, но изменить его духовную культуру они не могли. С конфуцианской точки зрения, этические требования преодолевать сопротивление с помощью не насилия, а добродетельного примера, надлежащего ритуала, этикета означает, что конфуцианский этноцентризм должен принять форму убеждения, сделать так, чтобы другие чувствовали себя в конфуцианской среде как дома, продемонстрировать свое «превосходство» настолько явно, чтобы они приняли его порядок [8]. Китай и сегодня активно способствует распространению своей культуры в мире и расширяет сферу своего политического влияния. Однако конфуцианство не распространилось бы так широко, не сохранило бы так на долго свое влияние, если бы оно было полностью закрыто от обратного влияния других культур.

Гражданская идентичность монгольских студентов взаимосвязана с ценностно-культурными ориентациями, компонентами этнической идентичности, толерантностью:

Эмоциональный компонент гражданской идентичности коррелирует с установками на динамически развивающуюся культуру $(\mathrm{r}=0,320, \mathrm{p}=0,05)$; когнитивным компонентом межкультурной компетентности (стремлением больше узнать о принимающей стороне $(\mathrm{r}=0,434, \mathrm{p}=0,005)$ и ее культуре $(\mathrm{r}=0,367, \mathrm{p}=0,05))$.

Чем выше показатели поведенческого компонента гражданской идентичности, тем более выражены ориентации на современную культуру ( $\mathrm{r}=0,351$, $\mathrm{p}=0,05)$, меньше желание знакомиться с культурой принимающей стороны $(\mathrm{r}=-0,420, \mathrm{p}=0,007)$, менее выражено стремление к общению с представителями других национальностей $(\mathrm{r}=-0,504, \mathrm{p}=0,001)$; ниже показатели этнофанатизма $(\mathrm{r}=-0,398, \mathrm{p}=0,05)$.

Уровень гражданской идентичности умеренно связан с толерантностью как чертой личности $(\mathrm{r}=0,417, \mathrm{p}=0,007)$, и в тоже время с возможной агрессивностью к другим народам $(\mathrm{r}=0,374, \mathrm{p}=0,05)$; обнаружена прямая связь с этноизоляционизмом $(\mathrm{r}=0,245, \mathrm{p}=0,05)$, и обратная с этнофанатизмом $(\mathrm{r}=-0,429$, $\mathrm{p}=0,05)$.

\section{Baikal Research Journal}




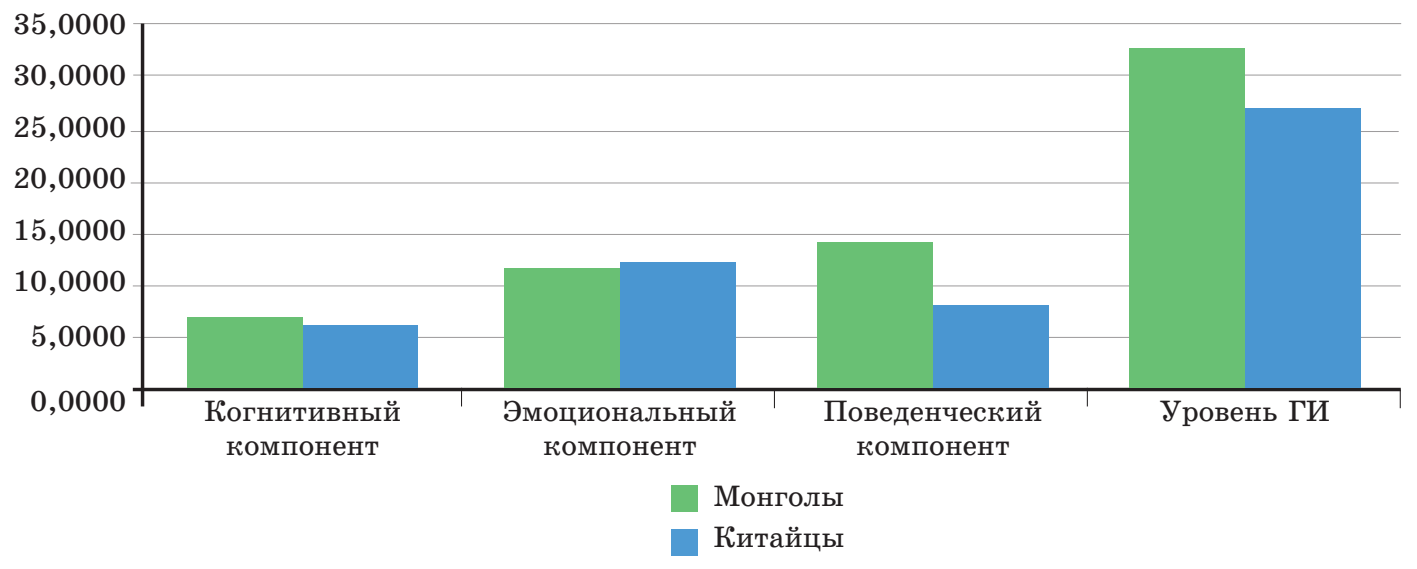

Рис.1. Сравнение средних значений колпонентов гражданской идентичности китайских и лонгольских студентов

Сравнение средних по критерию Стьюдента показало наличие значимых различий только в поведенческом компоненте $\left(\mathrm{M}_{\mathrm{M}}=13,6 ; \mathrm{M \kappa}=8,5 ; \mathrm{p}=0,001\right)$ и в целом в уровне проявления гражданской идентичности $(\mathrm{Mм}=32,8 ; \mathrm{M \kappa}=27,1$; $\mathrm{p}=0,001$ ) (рис. 1). Это полностью согласуется с результатами корреляционного анализа и, на наш взгляд, может быть обусловлено культурно-ценностными ориентациями, традициями, социальными нормами, политическими и религиозными идеями Китая и Монголии.

\section{Этническая идентичность}

Сравнение средних значений типов этнической идентичности китайских и монгольских студентов было проведено по критерию Стьюдента (рис. 2).

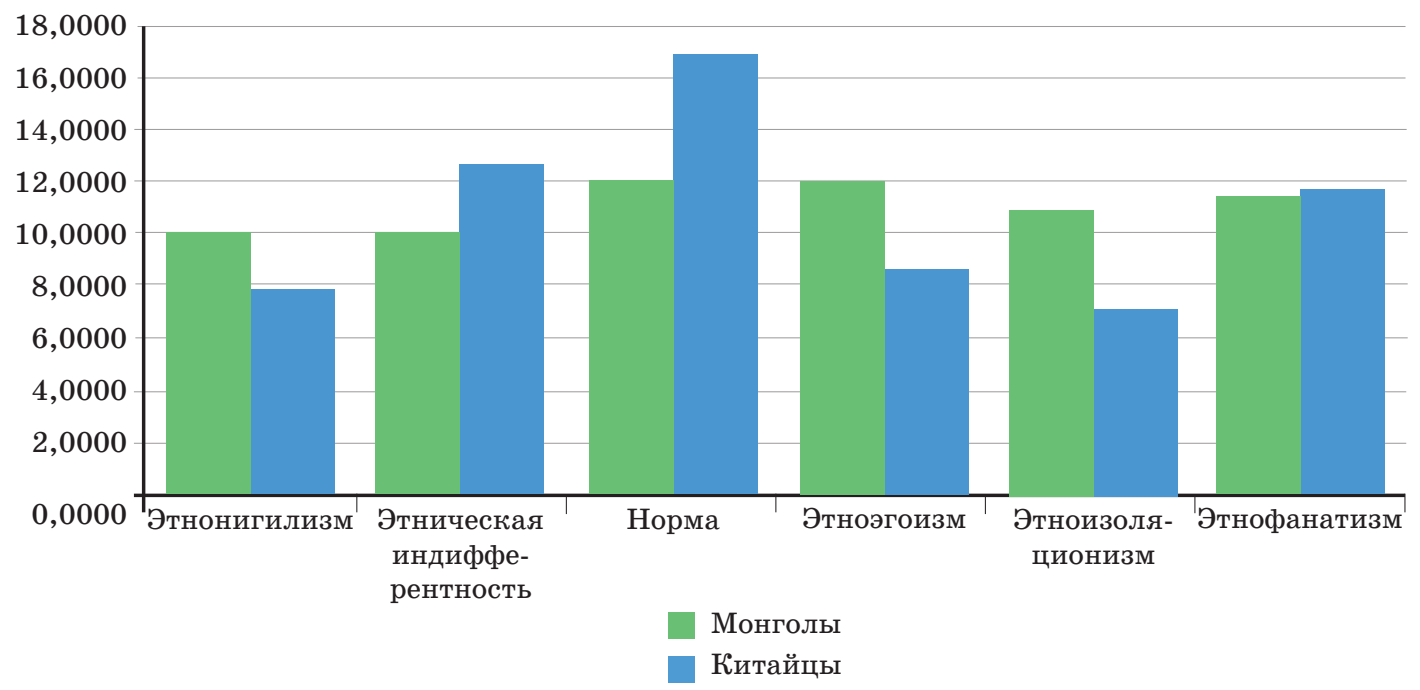

Рис. 2. Сравнение средних значений типов этнической идентичности китайских и монгольских студентов по критерию Стьюдента

Из рис. 2 видно, что значимые различия наблюдаются по всем типам этнической идентичности, кроме этнофанатизма.

\section{Baikal Research Journal}


Интересные связи у монгольских студентов выявились по такому типу этнической идентичности как этническая индифферентность: с установками на традиционную культуру $(\mathrm{r}=0,324, \mathrm{p}=0,05)$, и обратная с ориентациями на динамически развивающуюся культуру $(\mathrm{r}=-0,348, \mathrm{p}=0,05)$, также положительные связи с этнической толерантностью $(\mathrm{r}=0,483, \mathrm{p}=0,002)$, социальной толерантностью $(\mathrm{r}=0,658, \mathrm{p}=0,000)$, уровнем толерантности $(\mathrm{r}=0,611, \mathrm{p}=0,000)$.

Позитивная этническая идентичность коррелирует с уровнем перцептивно-невербальной компетентности $(\mathrm{r}=0,364, \mathrm{p}=0,05)$, социальной толерантностью $(\mathrm{r}=0,597, \mathrm{p}=0,000)$, уровнем толерантности $(\mathrm{r}=0,451, \mathrm{p}=0,003)$, когнитивным компонентом межкультурной компетентности $(\mathrm{r}=0,470, \mathrm{p}=0,002)$, ценностным компонентом межкультурной компетентности (понимание необходимости уважения ценностей, традиций, культуры других народов $(\mathrm{r}=0,380, \mathrm{p}=0,05)$.

Этноизоляционизм имеет положительную связь с уровнем перцептивно-невербальной компетентности $(\mathrm{r}=0,499, \mathrm{p}=0,001)$, и агрессивностью в отношении других народов $(\mathrm{r}=0,500, \mathrm{p}=0,001)$; этнофанатизм - с этнической толерантностью $(\mathrm{r}=0,380, \mathrm{p}=0,05)$ и обратно коррелирует с толерантностью как чертой личности $(-0,368, \mathrm{p}=0,05)$.

Следовательно, по мнению монгольских студентов: приверженность традициям, толерантность = этнической индифферентности, возможно, в контексте отсутствия стремления позиционировать свой народ на мировом уровне. Чем выше способность понимать невербальные проявления в общении, выявлять скрытые мотивы поведения, тем более выражено стремление к обособлению и осознание превосходства своего этноса, оправдание агрессии в отношении других, то есть готовности воспринимать других как угрожающих национальной безопасности. И этнофанатизм и этноизоляционизм могут тогда рассматриваться как механизмы защиты.

У китайских студентов установлены положительные взаимосвязи с перцептивно-невербальной компетентностью позитивной этнической идентичности ( $\mathrm{r}=0,333$, $\mathrm{p}=0,007)$, этнонигилизма $(\mathrm{r}=0,543, \mathrm{p}=0,013)$, этноэгоизма $(\mathrm{r}=0,447, \mathrm{p}=0,001)$, этноиндифферентности $(\mathrm{r}=0,345, \mathrm{p}=0,005)$, этноизоляционизма $(\mathrm{r}=0,398, \mathrm{p}=0,001)$, что на наш взгляд можно трактовать как проявление специфически китайской адаптивности и даже предприимчивости в любых ситуациях вне зависимости от собственных позиций. И только опосредованно через перцептивно-невербальную компетентность выявлена обратная связь с социальной толерантностью $(\mathrm{r}=0,314, \mathrm{p}=0,049)$, как негативное отношение к социальным порокам, в первую очередь.

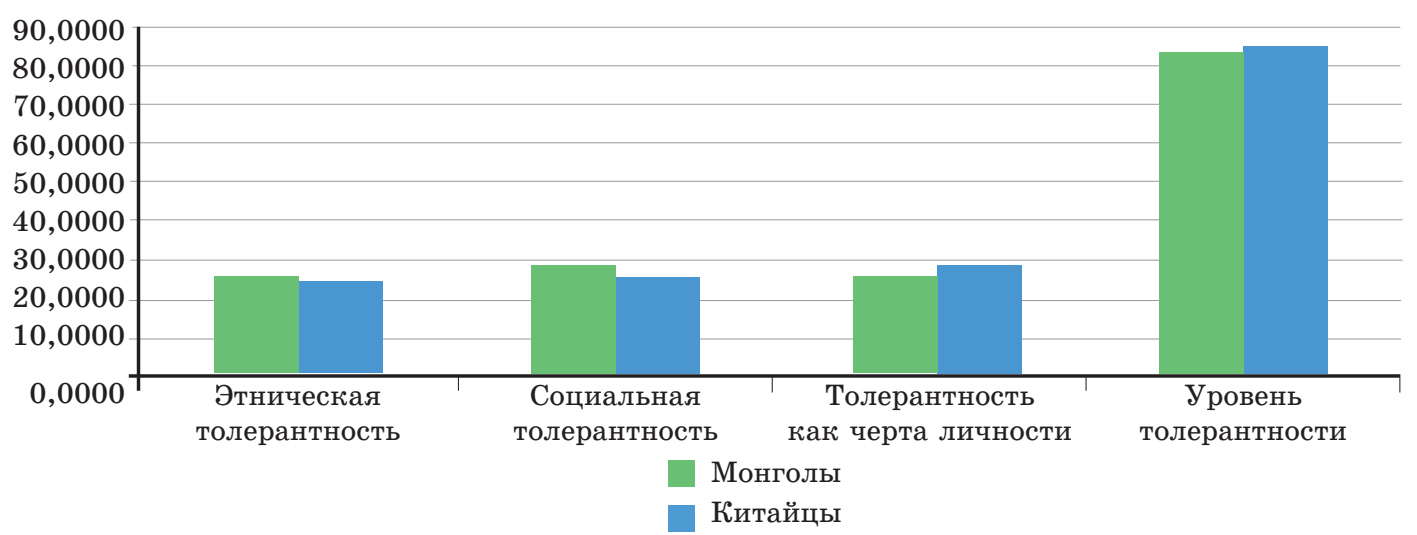

Рис. 3. Сравнение средних значений типов этнической идентичности по критерию Стьюдента китайских и монгольских студентов

\section{Baikal Research Journal}

электронный научный журнал Байкальского государственного университета 


\section{Толерантность}

Толерантность признается как актуальная проблема и важнейшая ценность сосуществования людей в поликультурном и полиэтническом обществе и при этом - именно система образования признается основной площадкой для реализации программы развития толерантных отношений в обществе $[9 ; 10]$.

Комментируя эмпирические исследования толерантности, отметим, что в целом по выборке китайских студентов преобладает средний и высокий уровень толерантности. В структуре компонентов толерантности у студентов-китайцев более выражена толерантность как черта личности $($ Мк $=28,2, \mathrm{p}=0,001)$, а у студентов-монголов - этническая толерантность $\left(\mathrm{M}_{\mathrm{M}}=27,02, \mathrm{p}=0,003\right)$ и социальная толерантность (Мм $=29,4, \mathrm{p}=0,005)$ (рис. 3). Это говорит о том, что толерантность китайских студентов базируется на их личностной самоидентификации, декларируется (хоть и опосредованно) на уровне нормы, а также проявляется в готовности к проявлению терпимости в реальных взаимодействиях и в понимании, проявлении интереса к иному мнению.

В структуре компонентов толерантности у студентов-монголов уровень толерантности ярко проявился в этнической $(\mathrm{M} м=27,02, \mathrm{p}=0,015)$ и социальной толерантности $(\mathrm{Mm}=29,4, \mathrm{p}=0,02)$. Это говорит о том, что толерантность монголов-студентов декларируется на уровне нормы с ориентацией на его личностную самоидентификацию, базируется на эмоциях, чувствах, переживаниях, понимании, проявлении интереса к иному мнению и определяет то, что для личности важно, хорошо, желательно, приемлемо.

В целом, средние показатели видов толерантности, а также компонентов толерантности у студентов обеих национальностей отличаются несущественно, только по двум компонентам имеются достоверные различия по Т-критерию Стьюдента: социальная толерантность (монгольские студенты проявляют больше толерантности по отношению к представителям другого пола) и толерантность как черта личности (у китайских студентов выше готовность к взаимодействию, они проявляют больше уравновешенности, терпеливости в поведении, чем студенты-монголы).

Уровень толерантности китайских студентов имеет тесные положительные внутренние связи с этнической толерантностью $(\mathrm{r}=0,879, \mathrm{p}=0,001)$, социальной толерантностью $(\mathrm{r}=0,540, \mathrm{p}=0,025)$ и толерантностью как чертой личности $(\mathrm{r}=0,575, \mathrm{p}=0,045)$. А у монгольских студентов уровень толерантности имеет не только внутренние положительные связи с этнической и социальной толерантностью $(\mathrm{r}=0,672, \mathrm{p}=0,001)$, позитивной этнической идентичностью $(\mathrm{r}=0,451$, $\mathrm{p}=0,012)$, но и опосредованно с этнической индифферентностью $(\mathrm{r}=0,483$, $\mathrm{p}=0,001)$, этноэгоизмом $(\mathrm{r}=0,425, \mathrm{p}=0,005)$.

\section{Культурно-иенностные ориентации}

При исследовании культурно-ценностных ориентаций китайских студентов выявлены внутренние отрицательные корреляции традиционной культуры с современной $(\mathrm{r}=-0,594, \mathrm{p}=0,001)$ и динамически развивающейся $(\mathrm{r}=-0,486$, $\mathrm{p}=0,001)$ культурами. Среднее значение по современной культуре в два раза превышает средние по традиционной и динамично развивающейся культурам. В своей основе китайские студенты являются сторонниками и последователями современной культуры. Это можно обосновать конфуцианской дихотомией «культурные заимствования (инновации) - традиционализм», раскрывающей отношение Китая к инокультурным элементам и их адаптацию на своей культурной почве. В данном случае китайская традиционная парадигма ( сущность - функция») используется для самоопределения китайской культуры, т.е «сохраняя свою духовную традицию, используем западные науку и технологии» [8]. Вместе с тем

\section{Baikal Research Journal}

электронный научный журнал Байкальского государственного университета 
следует отметить, что китайцы с большим интересом изучают иностранный опыт и все, что кажется им полезным, используют у себя в стране.

Выбор стратегии аккультурации особенно обостряет конкуренцию установок у представителей монгольской национальности, причем с традиционной культурой связана этническая индифферентность $(\mathrm{r}=0,324, \mathrm{p}=0,001)$, таким образом, приверженность сложившимся обычаям и традициям (которая обычна, присуща монгольской национальности) воспринимается как неактуальность этничности, может быть незаинтересованность в развитии, пассивность.

\section{Социальная дистанция в общении}

Для измерения степени близости или отчужденности между группами использовалась шкала социальной дистанции Э. Богардуса. Самая минимальная дистанция у китайцев выявлена к представителям своей же национальности, на втором месте, в числе самых предпочитаемых китайцами групп оказались русские, то есть большинство китайских студентов готовы принять русского как близкого друга, монголов скорее воспринимают как соседей, коллег по работе, от бурят предпочитают дистанцироваться. Для монгольских студентов наиболее предпочтительными являются представители своей национальности, близкими друзьями монголы считают русских, как к соседям относятся к бурятам, а с китайцами ориентированы на деловые отношения.

\section{Выводы}

Следует обратить внимание на общую закономерность: на обеих выборках обнаружена внутренняя положительная связь между компонентами гражданской идентичности. Высокая степень ощущения себя частью своего государства и народа, но наличие при этом эмоционального дискомфорта, сохранение тесных связей со своей Родиной, культурой и приближение ряда ментальных характеристик к иноязычному мировосприятию, демонстрируют о специфичности стратегии адаптации китайцев и монголов к культуре других этносов.

Целый ряд проведенных нами психологических исследований китайских студентов показал, что компоненты гражданской идентичности практически не имеют связи с этнической идентичностью, толерантностью, культурно-ценностными ориентациями, но опосредованно через перцептивное взаимодействие позволяют им влиять на них. Возможно, такого рода структурно-уровневая организация гражданской идентичности китайских студентов и является тем стержнем, который позволяет сохранять традиционные корни китайской культуры, проявляющиеся в современной культуре и адаптироваться в инокультурной среде.

Отсутствие корреляций между позитивной этнической идентичностью (нормой) и этнической толерантностью (хотя на монгольской выборке выявлены положительные связи с социальной толерантностью) можно трактовать как озабоченность своей национальной безопасностью и осторожным отношением к проявлениям толерантности в отношении других народов. Это подтверждается наличием группы связей у студентов-монголов уровня гражданской идентичности с этноизоляционизмом и готовностью проявлять агрессивность к другим народам, а этническая толерантность коррелирует с этнической индифферентностью и этнофанатизмом, то есть принимается скорее с позиции безразличия или игнорирования различий.

\section{Список использованной литературы}

1. Психология кризисных и экстремальных ситуаций : индивидуальные жизненные кризисы; агрессия и экстремизм : учебник / под ред. Н. С. Хрусталевой. - СПб. : Изд-во СПбГУ, 2016. - 372 с.

\section{Baikal Research Journal}


2. Баева И. А. Экстремальная ситуация в контексте психологии безопасности / И. А. Баева // Психология экстремальных ситуаций / под ред. В. В. Рубцова, С. Б. Малых. - М. : Психолог. ин-т РАО, 2008. - С. 110-125.

3. Краснощеченко И. П. Социально-психологическая адаптация студентов-мигрантов и трудовых мигрантов / И. П. Краснощеченко, Д. П. Ковдюк // Психологические науки. 2015. - № 8 (39), ч. 5. - С. 38-41.

4. Митин Д. Н. Образовательная (учебная) миграция: понятие, проблемы и пути решения / Д. Н. Митин // Вестник РУДН. Сер. Политология. - 2010. - № 3. - С. 123-133.

5. Большакова О. Б. Зарубежные концептуальные модели межкультурной компетентности / О. Б. Большакова, Т. А. Терехова // Психология в экономике и управлении. 2012. - № 1. - С. 84-96.

6. Карнышев А. Д. Межэтническое взаимодействие и межкультурная компетентность / А. Д. Карнышев, М. А. Винокуров, Е. Л. Трофимова. - Иркутск : Изд-во БГУЭП, 2009. $310 \mathrm{c}$.

7. Карнышев А. Д. Методы исследования и оптимизации межэтнического взаимодействия / А. Д. Карнышев, Е. Л. Трофимова. - Иркутск : Изд-во БГУЭП, 2007. - 224 с.

8. Терехова Н. В. Толерантность в условиях китайской народной традиции / Н. В. Терехова, Т. А. Терехова // Явные и скрытые смыслы культурной коммуникации. - Познань, 2014. - С. 73-81.

9. Терехова Т. А. Научно-педагогические традиции и инновации кафедры социальной и экономической психологии / Т. А. Терехова, Е. Л. Трофимова // Известия Иркутской государственной экономической академии (БГУЭП). — 2015. — Т. 25, № 2. — С. 330-335. DOI 10.17150/1993-3541.2015.25(2).330-335.

10. Трофимова Е. Л. Исследование видов и уровней толерантности у студентов / Е. Л. Трофимова // Психология в экономике и управлении. - 2012. — № 2. — С. 64-72.

\section{References}

1. Khrustaleva N S. (ed.). Psikhologiya krizisnykh i ekstremal'nykh situatsii: individual'nye zhiznennye krizisy; agressiya $i$ ekstremizm [Psychology of crisis and extreme situations: individual life crises; aggression and extremism]. Saint Petersburg, State University Publ., 2016. $372 \mathrm{p}$.

2. Baeva I. A. Extreme situation in the context of psychological security. In Rubtsov V. V., Malykh S. B. Psikhologiya ekstremal'nykh situatsii [Psychology of Extreme Situations]. Moscow, Psychological Institute of the Russian Academy of education, 2008. pp. 110-125. (In Russian).

3. Krasnoshchechenko I P., Kovdyuk D. P. Social Adaptation of Migrants: Students and Workes. Psikhologicheskie nauki = Psychology, 2015, no. 8 (39), iss. 5. pp. 38-41. (In Russian).

4. Mitin D. N. Educational Migration: the Notion, Problems and Ways of Solution. Vestnik RUDN. Seriya: Politologiya $=$ RUDN Journal of Political Science, 2010, no. 3, pp. 123-133. (In Russian).

5. Bolshakova O B., Terekhova T. A. Foreign conceptual models of intercultural competence. Psikhologiya $v$ ekonomike $i$ upravlenii $=$ Psychology in economics and management, 2012, no. 1, pp. 84-96. (In Russian).

6. Karnyshev A. D., Vinokurov M. A., Trofimova E. L. Mezhetnicheskoe vzaimodeistvie $i$ mezhkul'turnaya kompetentnost' [Interethnic interaction and intercultural competence]. Irkutsk, Baikal State University of Economics and Law Publ., 2009. 310 p.

7. Karnyshev A. D., Trofimova E. L. Metody issledovaniya i optimizatsii mezhetnicheskogo vzaimodeistviya [Research methods and optimization of interethnic interaction]. Irkutsk, Baikal State University of Economics and Law Publ., 2007. 224 p.

8. Terekhova N. W., Terekhova T. A. Tolerance under the Chinese Cultural Tradition. Explicit and implicit meanings of cultural communication. Poznan, 2014. pp. 73-81. (In Russian).

9. Terekhova T. A., Trofimova E. L. Scientific and pedagogical traditions and innovations of the Department of Social and Economic Psychology. Izvestiya Irkutskoi gosudarstvennoi ekonomicheskoi akademii = Izvestiya of Irkutsk State Economics Academy, 2015, vol. 25, no. 2, pp. 330-335. (In Russian). DOI 10.17150/1993-3541.2015.25(2).330-335.

\section{Baikal Research Journal}


10. Trofimova E. L. Research of types and levels of tolerance at students. Psikhologiya $v$ ekonomike $i$ upravlenii $=$ Psychology in economics and management, 2012, no 2, pp. 64-72. (In Russian).

\section{Информация об авторе}

Трофилова Елена Леонидовна - кандидат психологических наук, доцент, кафедра социальной и экономической психологии, социологии и социальной работы, Байкальский государственный университет, 664003, г. Иркутск, ул. Ленина, 11, e-mail: trofimova-bgy@mail.ru.

Терехова Татьяна Александровна - доктор психологических наук, профессор, кафедра общей психологии Иркутский государственный университет 664003, г. Иркутск, К. Маркса, 1 e-mail: terehovata@mail.ru

\section{Author}

Yelena L. Trofimova - PhD in Psychology, Associate Professor, Chair of Social and Economic Psychology, Sociology and Social Work, Baikal State University, 11 Lenin St., 664003, Irkutsk; e-mail: trofimova-bgy@mail.ru.

Tatiana A. Terekhova - Doctor habil. in Psychology, Professor, Chair of General Psychology, Irkutsk State University, 1 K. Marx St., 664003, Irkutsk; e-mail: terehovata@mail.ru

\section{Для цитирования}

Трофимова Е. Л., Терехова Т. А. Межэтническое взаимодействие студентов из стран ATP как условие психологической безопасности / Е. Л. Трофимова, Т.А. Терехова // Baikal Research Journal. - 2017. - T. 8, № 4. - DOI : 10.17150/2411-6262.2017.8(4).5.

\section{For Citation}

Trofimova Ye. L., Terekhova T. A. Interethnic interaction of students from the APR countries as a condition of psychological security. Baikal Research Journal, 2017, vol. 8, no. 4. DOI: 10.17150/2411-6262.2017.8(4).5. (In Russian).

\section{Baikal Research Journal}

